\title{
DEFECT STRUCTURE OF PRESSURE TREATED CZOCHRALSKI GROWN SILICON INVESTIGATED BY X-RAY TOPOGRAPHY AND DIFFRACTOMETRY
}

\author{
A. Misiuk \\ Institute of Electron Technology, Al. Lotników 32/46, 02-668 Warszawa, Poland \\ J. HÄrtwig, E. Prieur, M. Ohler
}

European Synchrotron Radiation Facility, BP 220, 38043 Grenoble, France

J. Bą-Misiuk, J. Domagala

Institute of Physics, Polish Academy of Sciences

Al. Lotników 32/46, 02-668 Warszawa, Poland

AND B. SURMa

Institute of Electronic Materials Technology, Wỏłczyńska 133, 01-919 Warszawa, Poland

The defect structure of Czochralski grown silicon single crystals annealed at $870-1400 \mathrm{~K}$ under hydrostatic pressure up to $1 \mathrm{GPa}$ was investigated by conventional and synchrotron radiation $\mathrm{X}$-ray topography and by reciprocal space mapping. Hydrostatic pressure promotes oxygen precipitation from oversaturated $\mathrm{Si}-\mathrm{O}$ solid solution and the creation of structural defects.

PACS numbers: $61.10 .-\mathrm{i}, 61.72 . \mathrm{Yx}, 81.40 . \mathrm{Vw}$

\section{Introduction}

The material response on stress at high temperature is of fundamental interest. In the case of silicon it is important also for its application in microelectronics. Valuable data concerning this subject were obtained for Czochralski grown silicon single crystals $(\mathrm{Cz}-\mathrm{Si})$ by annealing them under enhanced hydrostatic pressure (HP) $[1,2]$. Such treatment introduces stress into $\mathrm{Cz}-\mathrm{Si}$ and influences oxygen precipitation and creation of defects.

The following stress-related effects in as-grown and preannealed $\mathrm{Cz}-\mathrm{Si}$ were studied by conventional and synchrotron radiation X-ray topography and reciprocal space mapping: 
- creation (at $870-1000 \mathrm{~K}$ ) of nucleation centers (NCs) for further (at 1230-1400 K) oxygen precipitation, and

- enhanced oxygen precipitation at 1230-1400 K [2].

The effect of annealing at $1230-1400 \mathrm{~K}$ under $10^{5} \mathrm{~Pa}$ (atmospheric pressure) on the $\mathrm{Cz}-\mathrm{Si}$ samples with NCs created under stress was also investigated.

\section{Experimental}

(100) oriented $\mathrm{Cz}-\mathrm{Si}$ samples, of about $600 \mu \mathrm{m}$ thicknesses, with an initial oxygen concentration $\left(c_{0}\right)$ up to $1 \times 10^{18} \mathrm{~cm}^{-3}$ were investigated. Some of them were preannealed at $1020 \mathrm{~K}$ under $10^{5} \mathrm{~Pa}$ for 8 hours to create the "atmospheric pressure NCs".

The as-grown and preannealed samples were annealed next for 5-10 hours at $870-1400 \mathrm{~K}$ under argon pressures up to $1 \mathrm{GPa}$.

Additional annealing at $1230-1400 \mathrm{~K}$ under $10^{5} \mathrm{~Pa}$ was performed on some samples with NCs to investigate an effect of HP applied during the nucleation stage on oxygen precipitation.

A surface layer of about $30 \mu \mathrm{m}$ thickness was etched away after cooling. The samples were investigated by conventional and synchrotron radiation X-ray topography as well as by reciprocal lattice mapping supplemented by Fourier transform infrared spectrometry (FTIR) and selective chemical etching.

\section{Results and discussion}

$\mathrm{Cz}-\mathrm{Si}$ can be considered as a supersaturated solid solution of oxygen in the silicon matrix. The decay of this $\mathrm{Si}-\mathrm{O}$ solid solution at higher temperatures - IIP is an effect of approaching the thermodynamic equilibrium; the precipitated oxygen atoms form different defects.

Annealing $\mathrm{Cz}-\mathrm{Si}$ samples at $870-1020 \mathrm{~K}$ causes creation of nucleation centers for further oxygen precipitation, which takes place at higher temperatures, typically at $1230-1400 \mathrm{~K}$.

With increasing annealing temperature (within the $870-1000 \mathrm{~K}$ range) and pressure the interstitial oxygen concentration $c_{0}$ decreased, but only in the case of as-grown samples (Table). This means that there remained less interstitial oxygen in the crystal preannealed at $1020 \mathrm{~K}-10^{5} \mathrm{~Pa}$ and so more of it was precipitated to create "atmospheric pressure NCs".

$\mathrm{X}$-ray topographs of the $\mathrm{Cz}-\mathrm{Si}$ samples annealed at (870-1000) K - HP were typically featureless without recognizable defect images. This was an effect of presence in the $\mathrm{Cz}-\mathrm{Si}$ matrix of a high concentration $\left(\geq 10^{6} \mathrm{~cm}^{-3}\right)$ of small oxygen-related NCs.

In general the oxygen precipitates with diameters well below one micrometer show no resolvable topographic images. The defects with diameters in the order of one micrometer are normally well visible, because the related strain field is much wider than that. It is difficult to give an exact value for the visibility limit, because it depends on several parameters. The lateral resolution of the used topographic method was close to one micrometer.

Contrary to the nearly featureless X-ray topographs, the 400 reciprocal space maps indicated substantial diffuse scattering dependence on HP in the case of 


\section{TABLE}

The values of $c_{0}\left(\times 10^{-17}\right)\left[\mathrm{cm}^{-3}\right]$, determined by FTIR, for the as-grown $\mathrm{Cz}$-Si samples with initial $c_{0}=$ $1 \times 10^{18} \mathrm{~cm}^{-3}$ annealed under HP at $870 \mathrm{~K}$ for 10 hours or at $1000 \mathrm{~K}$ for 5 hours. The asterisk * means the $c_{0}$ values for the samples preannealed at $1020 \mathrm{~K}$ under $10^{5} \mathrm{~Pa}$ for 8 hours ( $c_{0}$ after preannealing was equal to $\left.8.8 \times 10^{17} \mathrm{~cm}^{-3}\right)$.

\begin{tabular}{c|c|c|c|c|c}
\hline \hline$T[\mathrm{~K}] \backslash \mathrm{HP}[\mathrm{Pa}]$ & $10^{5}$ & $10^{7}$ & $10^{8}$ & $6 \times 10^{8}$ & $10^{9}$ \\
\hline 870 & 10 & 10 & 9.8 & 8.3 & 8.2 \\
\hline 1000 & 8.4 & 8.7 & 8.7 & 8.7 & 5.6 \\
1000 & $7.8^{*}$ & $7.8^{*}$ & $7.8^{*}$ & $7.5^{*}$ & $7.8^{*}$
\end{tabular}

samples with NCs, especially when high values of HP were applied during annealing (Fig. 1).

Diffuse scattering (not close to the Bragg position) appears in general for defects with diameters well below one micrometer, that is when X-ray topographs no more show resolvable images. In this respect X-ray (synchrotron) topography and reciprocal space mapping are complementary.

The increase of diffuse scattering due to the effect of IIP on the creation of NCs was detected for as-grown $\mathrm{Cz}-\mathrm{Si}$ samples with a high initial interstitial oxygen concentration $\left(c_{0}=1 \times 10^{18} \mathrm{~cm}^{-3}\right)$ after treatment at $10^{9} \mathrm{~Pa}-1000 \mathrm{~K}$ for 5 hours (Fig. 1A, B). In the case of samples with lower $c_{0}\left(6.5-8 \times 10^{17} \mathrm{~cm}^{-3}\right)$ an increase of diffuse scattering due to HP was not detectable. A difference in diffuse scattering was visible if comparing the shapes of last contours of the same intensity.

The effect of HP was negligible also in the $\mathrm{Cz}-\mathrm{Si}$ samples with $\mathrm{NCs}$ created during preannealing at $1020 \mathrm{~K}$ under $10^{5} \mathrm{~Pa}$ for 8 hours and further annealed at $1000 \mathrm{~K}$ - HP (Table, Fig. 1C, D).

It follows that HP during annealing at $870-1000 \mathrm{~K}$ can promote the creation of NCs, probably on initially existing structural defects, but does not influence markedly the structure of samples with pre-existing NCs.

Annealing as-grown $\mathrm{Cz}-\mathrm{Si}$ at $1230-1400 \mathrm{~K}$ under HP caused enhanced oxygen precipitation, especially in the samples with high initial $c_{0}$ values [2]. For example, whereas the sample with initial $c_{0}=1 \times 10^{18} \mathrm{~cm}^{-3}$ showed a decrease in $c_{0}$ to $8.2 \times 10^{17} \mathrm{~cm}^{-3}$ after annealing for 5 hours at $1230 \mathrm{~K}$ at $10^{5} \mathrm{~Pa}$, the $c_{0}$ value for the same sample annealed at $1230 \mathrm{~K}$ under $10^{9} \mathrm{~Pa}$ was $3.4 \times 10^{17} \mathrm{~cm}^{-3}$. The effect of HP - stimulated oxygen precipitation was clearly seen on the topographs and reciprocal space maps (Fig. 2).

In the case of further annealing at $(1230-1400 \mathrm{~K})-10^{5} \mathrm{~Pa}$ of the samples with NCs produced by preannealing at $1000 \mathrm{~K}-\mathrm{HP}$ for 5 hours, an effect of HP applied during the nucleation stage was also detected, especially for the samples with NCs created at $10^{7}-10^{9} \mathrm{~Pa}$. For example, the $\mathrm{Cz}-\mathrm{Si}$ sample preannealed at $1000 \mathrm{~K}-10^{5} \mathrm{~Pa}$ for 5 hours (to create NCs) and later annealed for 5 hours at 

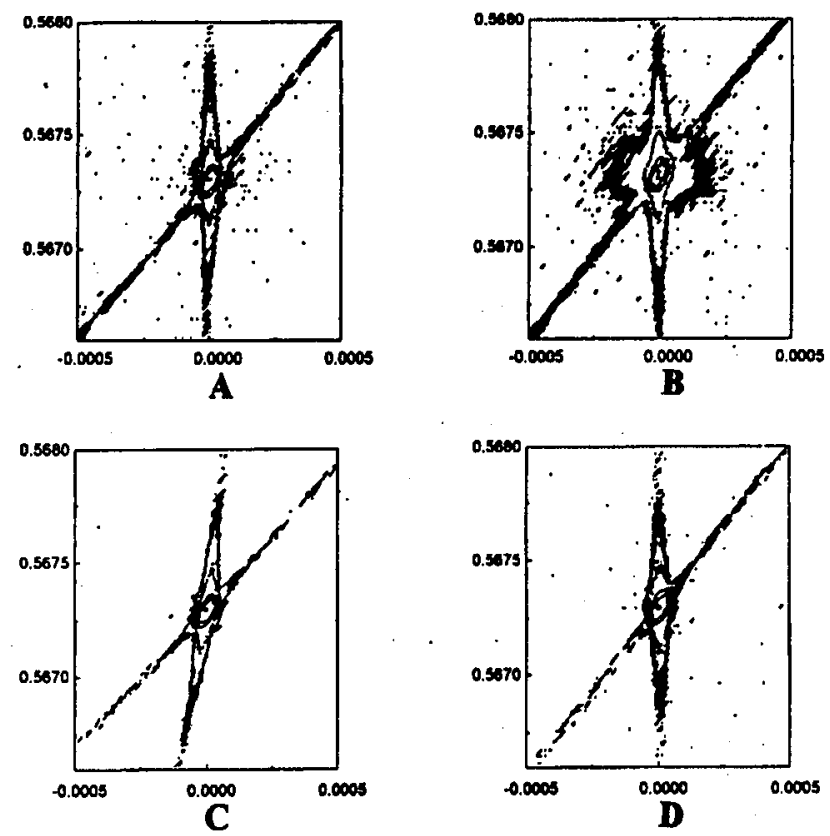

Fig. 1. Two-dimensional reciprocal space maps recorded near the 400 reciprocal-lattice point for the $\mathrm{Cz}-\mathrm{Si}$ samples with initial $c_{0}$ equal to $1 \times 10^{18}$ ( $\mathrm{A}$ and $\mathrm{B}$ samples) and $8.5 \times 10^{17} \mathrm{~cm}^{-3}$ (C and D samples, preannealed). $\mathrm{Cu} K_{\alpha}$ radiation $(\lambda \approx 0.1541 \mathrm{~nm})$. The axes are marked in $\lambda / 2 d$ units. $A$ and $B$ : As-grown samples subjected to annealing at $1000 \mathrm{~K}$ for 5 hours under $10^{7} \mathrm{~Pa}$ (sample $\mathrm{A}$ ) and $10^{9} \mathrm{~Pa}$ (sample $\mathrm{B}$ ). C and D: Samples with NCs created by preannealing at $1020 \mathrm{~K}$ under atmospheric pressure for 8 hours and later $\mathrm{HP}$ - treated at $1000 \mathrm{~K}$ for 5 hours under $10^{7} \mathrm{~Pa}$ and $10^{9} \mathrm{~Pa}$, respectively.

$1400 \mathrm{~K}-10^{5} \mathrm{~Pa}$, showed an oxygen concentration equal to $5.6 \times 10^{17} \mathrm{~cm}^{-3}$. After the same preannealing but under $10^{8} \mathrm{~Pa}$ and the same final annealing, the $c_{0}$ value was below $4 \times 10^{17} \mathrm{~cm}^{-3}$.

Our investigations by conventional and synchrotron radiation $\mathrm{X}$-ray topography and by reciprocal space mapping confirmed that HP promotes oxygen precipitation and creation of structural defects in $\mathrm{Cz}-\mathrm{Si}$ annealed at 870-1400 K under HP.

The measurements were also a test, if the results of reciprocal space mapping, done at the ESRF using higher energies in the transmission (Laue) case and investigating (and averaging over) the sample in its whole depth, are different from those using lower energies in the reflection (Bragg) case and investigating only a shallow surface layer (in the case of conventional equipment). Both kinds of mapping were complementary in this respect. For example, from the 400 reflection reciprocal space map of the $1230 \mathrm{~K}-10^{9} \mathrm{~Pa}$ treated sample it followed much higher disturbance of the sample surface layer as compared to the effect of treatment at $1230 \mathrm{~K}-10^{7} \mathrm{~Pa}$ (Fig. 2). The 220 reciprocal lattice space maps 

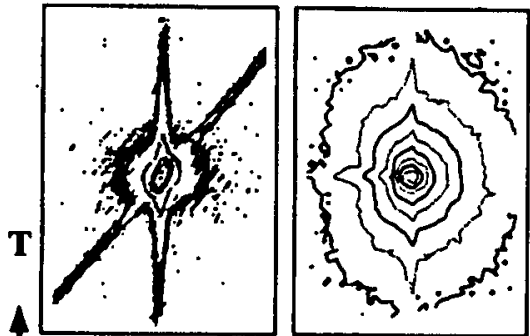

$1400 \mathrm{~K}-10^{7} \mathrm{~Pa}$

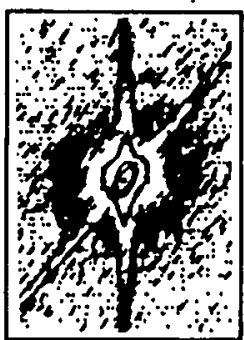

$1230 \mathrm{~K}-10^{7} \mathrm{~Pa}$

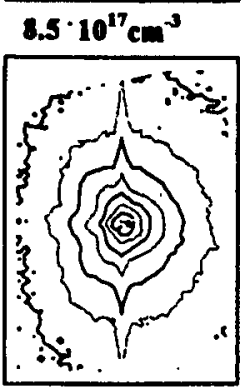

$7.5 \cdot 10^{17} \mathrm{~cm}^{-3}$

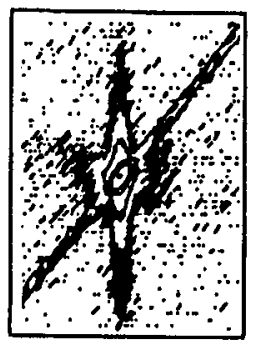

$1400 \mathrm{~K}-10 \mathrm{~Pa}$

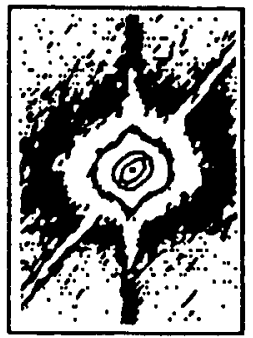

1230K-10'Pa

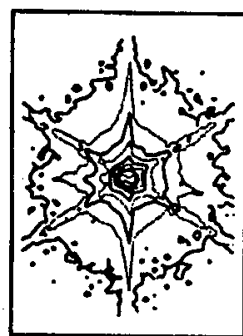

$7.6 \cdot 10^{17} \mathrm{~cm}^{-3}$

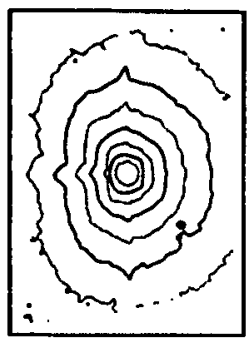

$3.5 \cdot 10^{17} \mathrm{~cm}^{-3}$

left: Brags case (8.048keV)

Fig. 2. Reciprocal space maps obtained for the 400 reflection (Bragg case, conventional X-ray source, $\mathrm{Cu} K_{\alpha}$ radiation, $\lambda \approx 0.1541 \mathrm{~nm}, E=8.048 \mathrm{keV}$, left in the figure) and for the 220 reflection (Laue case, $\lambda \approx 0.04 \mathrm{~nm}, E=15 \mathrm{keV}, \mathrm{BM} 5$ beam line at ESRF, right) on the $\mathrm{Cz}-\mathrm{Si}$ samples with initial $c_{0}=1 \times 10^{18} \mathrm{~cm}^{-3}$, subjected to HP treatment at indicated conditions. The concentrations of oxygen determined by FTIR after treatment are also indicated.

(Laue case) indicated, however, comparable HP - induced disturbance in sample bulk after both kinds of treatment.

\section{Acknowledgments}

The authors are indebted to Dr W. Jung, Mr T. Koska and M. Rozental from IET Warszawa for experimental assistance.

This work was supported partially by the grant No. 8T11B 04809 of the Committee for Scientific Research (Poland) and by the French-Polish Scientific and Technological Cooperation Joint Project No. 5197/6197.

\section{References}

[1] A. Misiuk, in: Solid State Crystals: Materials Science and Applications, Eds. J. Żmija, A. Rogalski, J. Zieliński, Proc. SPIE 2373, 335 (1995).

[2] A. Misiuk, B. Surma, J. Härtwig, Mater. Sci. Eng. B 36, 30 (1996). 